\title{
Proksimal tibia kırıklarının intramedüller çiviler ile tedavisinde karşılaşılan sorunlar ve çözüm yolları
}

\author{
Treatment of proximal tibial fractures with intramedullary nails \\ -problems and solutions
}

\author{
Hakan Özdemir
}

Akdeniz Üniversitesi Tıp Fakültesi Ortopedi ve Travmatoloji Anabilim Dalı, Antalya

\begin{abstract}
Tibia üst uç kırığını tedavi etmeyi planlayan ortopedist seçeceği tedavi yöntemine karar verirken, hastanın yaşı, aktivite düzeyi, genel tıbbi durumu ve beklentisini son derece iyi değerlendirmek mecburiyetindedir. Yapılan değerlendirmeler neticesinde tedavide intramedüller implantlardan yararlanılmasına karar verildiğinde ise karşılaşılabilecek sorunlar; kemik ile, kullanılan çivi veya teknik ile ilgili olabilir. Sayılan dezavantajları birbirinden ayırt etmek veya önem ve sıklık sırasına dizmek mümkün değildir. Bununla birlikte tekniğin; minimal invaziv olması, yapılan küçük kesinin kırık sahasından uzakta olması sayesinde enfeksiyon olasılığının düşük olması, uygulanan tespitin biyolojik olması gibi önemli avantajları bulunduğu da bir gerçektir. Bu avantajlar sayesinde, primer ve sekonder dizilim sorunlarının önüne geçilmesi kaydıyla, proksimal tibia kırıklarının intramedülller implantlar ile başarılı şekilde ve yüz güldürücü sonuçlar elde edilebilecek şekilde tedavi edilmeleri mümkündür.
\end{abstract}

Anahtar sözcükler: tibia; tibia üst uç kırığı; cerrahi tedavi; intramedüller çivi; intramedüller tespit

\begin{abstract}
An orthopedist planning to treat a proximal tibial fracture must consider the patients' age, activity level, overall medical condition, and expectation of recovery while deciding on the treatment method. If intramedullary implants are used for the treatment, potential problems that could be faced can be about the bone, the nail, or the technique. It is not possible to distinguish between these disadvantages or to sort them according to importance or frequency. Nevertheless, it is a fact that this technique has important advantages, such as: being minimally invasive, having low infection rate due to the small cut used in the procedure far from the fracture area, and the adopted fixation being biological. Thanks to these advantages, it is possible to successfully treat proximal tibial fractures with intramedullary implants, as long as primary and secondary alignment problems are prevented.
\end{abstract}

Key words: tibia; proximal tibial fracture; surgical treatment; intramedullary nail; intramedullary fixation

patolojik kırıkları, orta ve alt 1/3'deki transvers kırıklarda intramedüller çivi ile tespit yapılabilir. Yalnız tibia kanal ve çapı femur kadar düzgün olmadığından intramedüller çivi ile güvenilir bir tespit sağlanamaz ve rotasyon önlenemez. Aynı zamanda uzun süre alçı tespiti gerekebilir. Tibia dolaşımının 2/3'ünün endosteal yolla gelmesi ve çivinin bu endosteal dolanımı bozması, yağ embolisi, kırı̆̆ iyi tespit edememesi gibi sakıncaları olduğundan intramedüller çivi femurdaki kadar taraftar bulmamıştır" demektedir. Aynı bölüm, Lottes'in uygulamalarının sonuçlarına dayanılarak; "Rijit bir tespit sağlamak için kemik medüllası genişletilerek iliği dolduran kalın çiviler kullanılırsa medüller damarlanma bozulur. Eğer kanal genişletilmeden daha ince çiviler kullanılırsa damarlanma pek bozulmaz fakat rijit bir fiksasyon sağlanamaz.” şeklinde devam etmektedir. ${ }^{[1]}$

- İletişim adresi: Prof. Dr. Hakan Özdemir, Akdeniz Üniversitesi Tıp Fakültesi Ortopedi ve Travmatoloji Anabilim Dalı, Antalya Tel: 0242 - 2696000 / 2214 e-posta: hakanozdemir@akdeniz.edu.tr

- Geliş tarihi: 1 Eylül $2018 \quad$ Kabul tarihi: 1 Eylül 2018 
Ege'nin kitabında sözü edilen Lottes ise 1987 yılında yayımlanmış olan The Science and Practice of Intramedullary Nailing isimli kitapta; "Dizin $7,5 \mathrm{~cm}$. altı ve ayak bileğinin $7,5 \mathrm{~cm}$. üstündeki kırıklar Lottes çivisi adayıdırlar. Bu bölge dışında kalan kırıklar çivilenebilirse de, medüller kanalın genişliği nedeniyle arzu edilen düzeyde stabilite elde edilemez ve hastanın bir miktar deplasmanı kabul etmesi gerekir." demektedir. ${ }^{[2]}$

Biraz daha geri gittiğimizde, 1984 yılında yayımlanan Fractures'ın Fractures of the Tibia and Fibula bölümünün yazarı Leach; "Femur kırıklarının tedavisinde çok popüler olan intramedüller çiviler, tibia cisim kırıklarında aynı düzeye ulaşamamışlardır. Bunun nedeni; tibia cisim kırıklarının konservatif tedaviye uygun kırıklar olması, intramedüller çivileme tekniğinin çok da başarılı olmaması veya hastaların femur kırıklarındaki kadar çok immobilizasyona ihtiyaç duymamaları nedeniyle hekimlerin bu yönteme pek sıcak bakmamaları olabilir." demekte ve şöyle devam etmektedir; "Intramedüller çivilemeye en uygun iki kırık tipi; tibianın 1/3 orta kesimindeki parçalı olmayan transvers veya kısa oblik kırıklarla büyük deplasman veya angülasyon gösteren segmenter kırıklardır. Metod; 1/3 distal ve1/4 proksimal tibia kırıkları için uygun değildir. ${ }^{[3]}$ "

2000 yılında tercüme edilerek yayımlanan Kırık Tedavisinde AO Kuralları kitabında Watson; "Kanal içi çivileme tibianın kapalı orta gövde kırıkları ve yeterli yumuşak doku örtüsü olan kırıkları için kullanılır. Metafiz kırıklarında kısa parçaya hakim olmak ve uygun doğrultuda tutarak kontrol etmek zor olduğu için bu bölgede çoğu kez plak tercih edilir." ifadesini kullanmıştır. ${ }^{[4]}$

Birbirinden farklı yıllarda, yayımlanan kitaplarda farklı yazarların farklı şeyler söylemelerine rağmen üzerinde anlaştıkları tek nokta; tibia kırıklarının tedavisinde kullanılan intramedüller implantların, proksimal ve distal bölge kırıklarında yeterli stabiliteyi sağlayamamaları nedeniyle, bu bölge kırıklarının tedavisi için uygun olmadıklarıdır.

AO Müller klasifikasyon sisteminde üç temel gruba ayrılan tibia kırıklarının, alt gruplar da dikkate alındığında, 27 farklı tipi bulunmaktadır. Günümüzde bu kırık tiplerinin tedavi yöntemleri konusunda ortak bir görüş birliği oluşmuş durumdadır. Orta $1 / 3$ ve segmenter tibia kırıklarında intramedüller çivi uygulamaları altın standart iken, diğer bölgelerde açık redüksiyon-internal tespit, eksternal tespit ve alçı-breys ile tespit teknikleri tercih edilmektedir. Ancak, özellikle son 10 yıl içerisinde, intramedüller implant teknolojisinde gözlenen gelişmeler ve bu gelişmeye paralel olarak üretilmiş olan çiviler yeni endikasyonlar ortaya çıkarmıştır. Geçmişten gelen bilgi ve kötü tecrübelerin de etkisiyle, halen yaygın şekilde kabul görmüş olmamakla birlikte, eklem uzanımı olmayan veya eklem içi parçalanması minimal düzeyde olan proksimal ve distal tibia kırıkları da intramedüller implantlarla tespit edilmeye başlanmıştır.

Proksimal tibia kırıklarının intramedüller çivi ile tedavisindeki karşılaşılabilecek sorunlar; kemik ile, kullanılan çivi veya teknik ile ilgili olabilir. Sayılan dezavantajları birbirinden ayırt etmek ya da önem ve sıklık sırasına dizmek mümkün değildir. Bununla birlikte tekniğin; minimal invaziv olması, yapılan küçük kesinin kırık sahasından uzakta olması sayesinde enfeksiyon olasılığının düşük olması, uygulanan tespitin biyolojik olması gibi önemli avantajları bulunduğu da bir gerçektir.

Proksimal tibia kırıklarının intramedüller implantlarla tedavisi aşamasında en sık karşılaşılan sorun, yetersiz redüksiyon ve dizilim bozukluğudur. Proksimal tibia kırıklarında, çivinin bizzat kendisinin dizilimi sağladığı cisim kırıklarının aksine, çivi uygulanmadan önce doğru redüksiyon elde edilmemesi dizilim sağlanmadan kırığın tespit edilmesiyle sonuçlanacaktır. Oluşan primer dizilim sorunu yetersiz kemik-çivi temasına bağlı olarak gelişen instabiliteye bağlı sorununun da ana nedenidir.

Proksimal tibia kırı̆ı̆ sonrasında, sıklıkla, valgus deformitesi ve proksimal parçanın anterior angülasyonu söz konusudur. Bir koronal plan deformitesi olan valgus deformitesi; lateral kompartman kaslarının çekişine, lateral metafizer parçalanmaya, aynı seviyedeki fibula kırı̆̆ına veya çivinin giriş noktasındaki soruna bağlı olarak gelişir. Çivinin mediyal bir giriş noktası kullanılarak proksimal parça boyunca laterale doğru ilerletilmesi valgus, lateral giriş noktası kullanılarak mediyale doğru ilerletilmesi ise varus deformitesine neden olur (Şekil 1).

Bir sagittal plan deformitesi olan proksimal parçanın anterior angülasyonu ise, kuadriseps veya anterior kompartman kasları çekisine, posterior korteksin parçalanmasına, yanlış çivi tercihine veya çivi giriş noktasının normalden daha distalde olmasına bağlı olarak gelişir; $5^{\circ}$ 'den fazla açılanma, $10^{\circ}$ 'den fazla rotasyon ve $10 \mathrm{~mm}$ 'den fazla deplasmanı olan kırıkların osteartrite neden olduğu, açılanmanın $20^{\circ}$ 'nin üstüne çıkması durumunda ise, tibia aksı üzerindeki tüm kompartmanlardaki basıncın \%106 düzeyine ulaştığı bilindiğinden ${ }^{[5]}$, dizilim sorununu önlemek adına birçok teknik geliştirilmiştir. Bunlardan ikisi, redüksiyonun bir distraktör aracılığıyla sağlanması ve tibia mediyal yüzüne tek korteks vidalarla tespit edilen redüksiyon plaklarının (mickey-mouse plak) uygulanması gibi ekstrem tekniklerdir. Ancak gerçek çözüm; çivinin giriş noktasının özenle tespit edilerek daha posterior ve laterale kaydırılması, patellar tendon çeki gücünün azaltılması için çivinin diz semi-ekstansiyonda iken yerleştirilmesi, proksimal parçayı valgusa zorlayan deforman güçlerin önüne geçmek amacıyla Poller vidaların kullanılması ve 

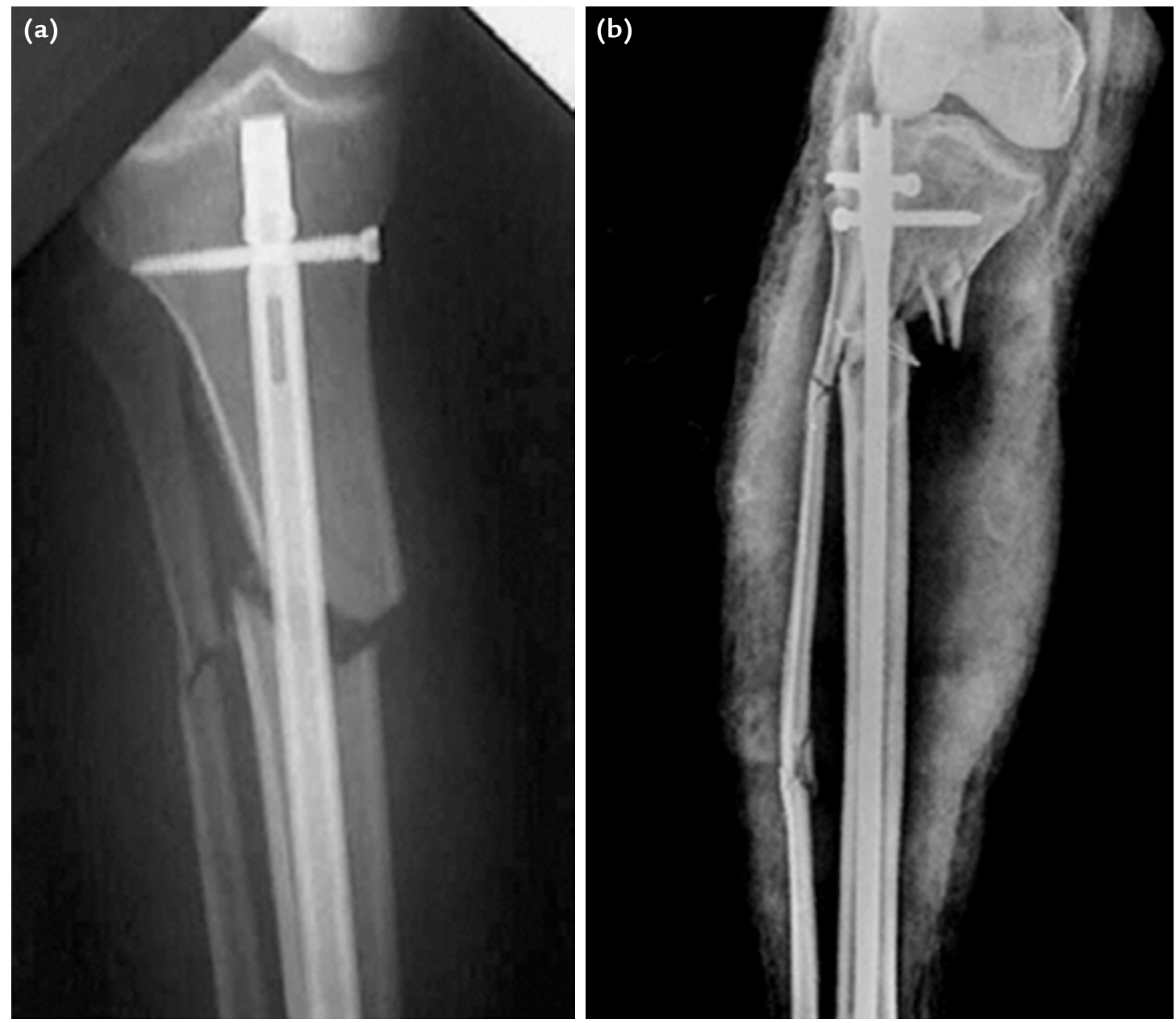

Şekil 1. a, b. Mediyal giriş (a) noktasının kullanılması valgus, lateral giriş (b) noktasının kullanılması ise varus deformitesine neden olur.

proksimal tibia anatomisine ve biyomekanik özelliklerine uygun implantların tercih edilmesinde saklıdır.

\section{GiRiş NOKTASı}

Tibia kırıklarının tedavisi amacıyla intramedüller çivi uygulamalarının en tehlikeli sorunlarından biri posterior korteksin yaralanmasıdır. Özellikle düz çivilerde sık karşılaşılan bu sorundan uzak kalabilmek adına, tarihsel süreçte Küntscher, giriş noktasını biraz daha proksimale kaydırmış ve eklem kıkırdağının zedelenme riskini göze almıştır. Herzog ise kendi çivisinin boyun kısmını açılandırarak, tibial giriş noktasını biraz daha aşağı çekmeyi hedeflemiştir. Giriş noktasının aşağıya indirilmesi, tibial eklem kıkırdağı harabiyetini azaltmış, ancak patellar tendon irritasyonu sorununu ortaya çıkartmıştır. ${ }^{[6]}$ Bu sorun, Lottes'in giriş noktasını biraz mediyale çekmesi ile giderilmeye çalışılmıştır. Ancak bu uygulama, özellikle proksimal tibia kırıklarında, valgus deformitesi gelişmesi ile sonuçlanmıştır.

Sonuç olarak, çivi giriş noktası birçok sorunun kaynağı gibi gözükmektedir ve kırı̆ga uygun giriş noktasının saptanması ile birçok sorunu ortaya çıkmadan önleyebilmek mümkündür.

Klasik bilgiye göre tibial çivi giriş noktası; tibianın ön yüzünde, tibial tüberkülün biraz üzerinde ve menisküs anterior boynuz yapışma noktalarının hemen önündedir (Şekil 2a). Ancak yapılan çalışmalar, insanların \%70'inde, tarif edilen bu alanda transvers bağın bulunduğunu göstermiştir (Şekil 2b). Böyle olunca $\mathrm{da}$, çivinin uygulanabileceği "safe zone"un biraz daha anteriora çekilmesi daha doğru olacak gibi gözükmektedir. Tibianın üç boyutlu incelenmesi sonucunda ortaya çıkan safe zone, anteriorda; patellar tendonun tibial tüberküle yapıştığı mediyal ve lateral noktalar ile 

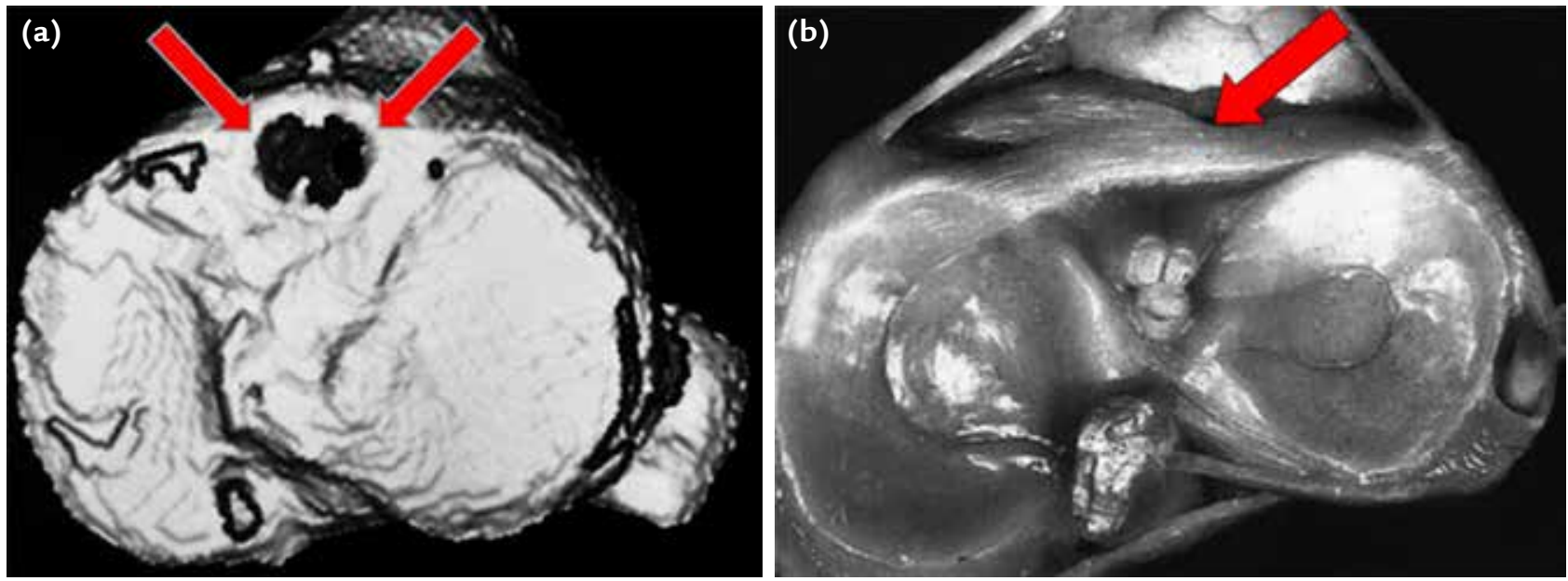

Şekil 2. a, b. Tibia kırıklarında intramedüller çivi giriş noktası; tibianın ön yüzünde, tibial tüberkülün biraz üzerinde ve menisküs anterior boynuz yapışma noktalarının hemen önündedir (a). Ancak, insanların \%70’inde, bu alanda transvers bağ bulunur (b).

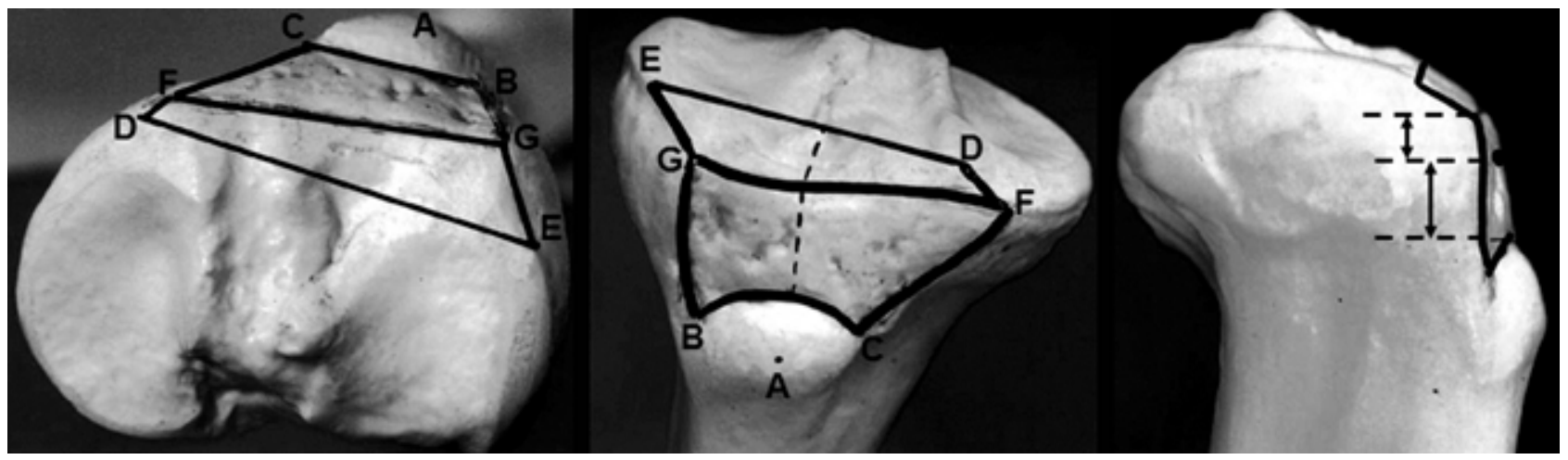

Şekil 3. Tibia kırıklarında intramedüller çivi uygulaması için safe zone, anteriorda; patellar tendonun tibial tüberküle yapıştığı mediyal ve lateral noktalar ile superiorda; mediyal menisküs ön boynuzunun yapışma noktası ve lateral tibial plato eklem yüzünü birleştiren çizgiler arasında kalan bölgedir (BCFG dörtgeni). Proksimal tibia kırıkları için doğru giriş noktası ise medüller kanal üzerinde, tibial eklem kıkırdağının $1 \mathrm{~cm}$. distalinde (fibula başı hizasında), tibia plato orta noktasının $1 \mathrm{~cm}$. laterali veya tibial tüberkül orta noktasının $3 \mathrm{~mm}$. lateralindedir.

superiorda; mediyal menisküs ön boynuzunun yapışma noktası ve lateral tibial plato eklem yüzünü birleştiren çizgiler arasında kalan bölgedir (Şekil 3). ${ }^{[7]}$ Eğer giriş noktası çok aşağıda ve çivinin açısı (Herzog eğimi) çok fazla ise tibianın posterior korteksinin, giriş noktası yukarıda ve çivinin açısı az ise tibial eklem kıkırdağının yaralanma riski artacaktır (Şekil 4). Aynı kötü olasılık, proksimal çapı gövde çapından daha geniş olan çivilerin kullanımı sırasında da söz konusudur.

Proksimal tibia kırıklarında görülen valgus ve ekstansiyon deformitesini gidermek için giriş noktasını normalden daha lateral ve posterior olarak belirlemek önemlidir. Proksimal tibia kırıkları için doğru giriş noktası; medüller kanal üzerinde, tibial eklem kıkırdağının $1 \mathrm{~cm}$ distalinde (fibula başı hizasında), tibia plato orta noktasının $1 \mathrm{~cm}$ laterali veya tibial tüberkül orta noktasının $3 \mathrm{~mm}$ lateralindedir (Şekil 3). Ancak bu durumda, lateral eklem kıkırdağı yaralanması oluşabileceği akıldan çıkartılmamalı ve özellikle awl'ın ilerletilmesi aşamasında çok dikkatli olunmalıdır. Dize anteriordan, patellar tendon içinden, ulaşacak bir ekspojurla bu sorundan biz nebze olsa da uzak kalabilmek mümkündür. Ancak bu durumda, Herzog eğimi az olan çivilerin özellikle de yüksek giriş aşamasında ciddi sorunlara neden olabileceği ve diz önü ağrısını arttırabileceği unutulmamalıdır.

\section{DiZiN POZisYONU}

Proksimal tibial kırıkların intramedüller implantlar ile tedavisindeki sorunlardan biri olan valgus ve ekstansiyon deformitesinin engellenmesinde dizin, çivinin uygulanması aşamasındaki, pozisyonu büyük önem taşır. 


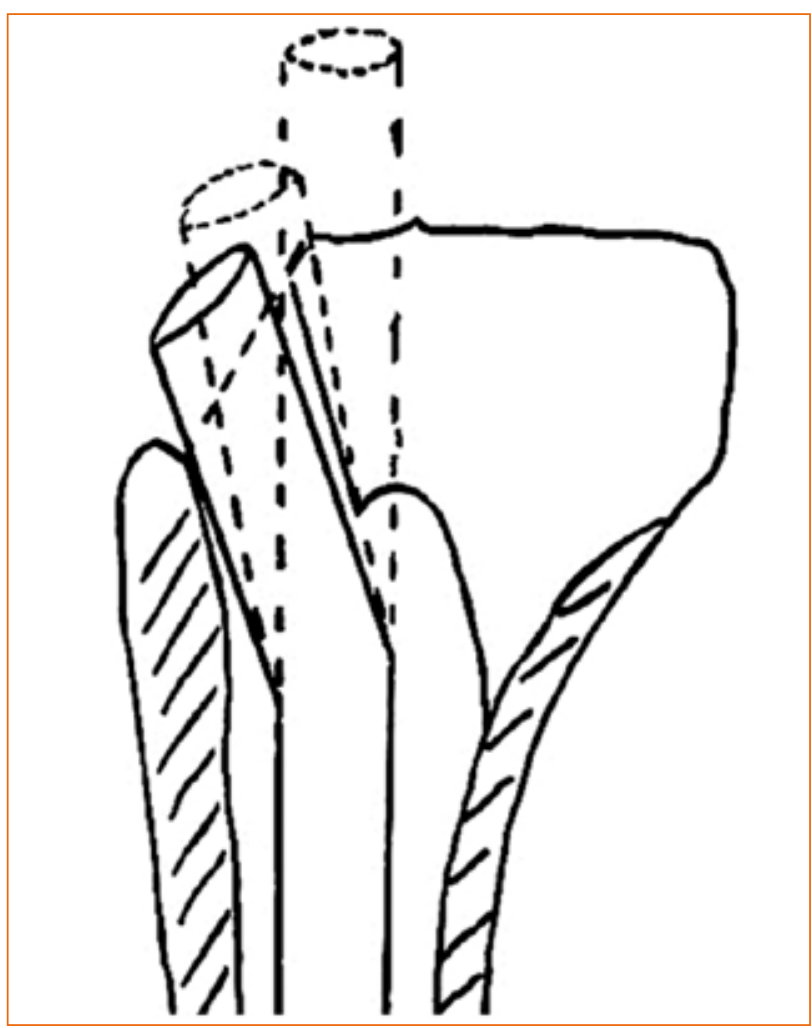

Şekil 4. İntramedüller çivi giriş noktası çok aşağıda ve çivinin Herzog eğimi fazla ise tibianın posterior korteksinin, giriş noktası yukarıda ve Herzog eğimi az ise tibial eklem kıkırdağının yaralanma riski artar.

Proksimal parçanın anterior angülasyonunun nedeni, kuadriseps kasının çekişidir. Giriş noktasını posteriora alabilmek adına dizin iyice fleksiyona zorlanması durumunda kuadriseps gerginliği de artacağından, proksimal parçanın anterior angülasyonu daha da belirginleşir (Şekil 5). Bu sorundan uzak kalabilmek için, çivinin uygulanması aşamasında, dizin semi-ekstansiyonda (yaklaşık $15^{\circ}$ fleksiyonda) tutulması önemlidir.

Patellar tendon üstünden yapılan kesilerle, varus veya valgus deformitesi olmadan, tam olarak medüller kanala ulaşmak mümkün olmakla birlikte, tendonun ekartörlerle mediyal ve laterale doğru çekilmesi prokurvatum deformitesi ile sonuçlanacaktır. Bu nedenle, proksimal tibia kırıkları için en çok savunulan yaklaşım, küçük bir lateral parapatellar artrotomi sonrasında patellanın, femoral sulkusa doğru itilmesidir. Ancak, bu işlemin oldukça zor olduğu ve bir kısım araştırmacı tarafından bu girişimi gerçekleştirebilmek için özel trokarlar geliştirildiği ve hatta işlemi kolaylaştırmak adına proksimal retropatellar tekniklerin denendiği akıldan çıkartılmamalıdır. ${ }^{[8]}$

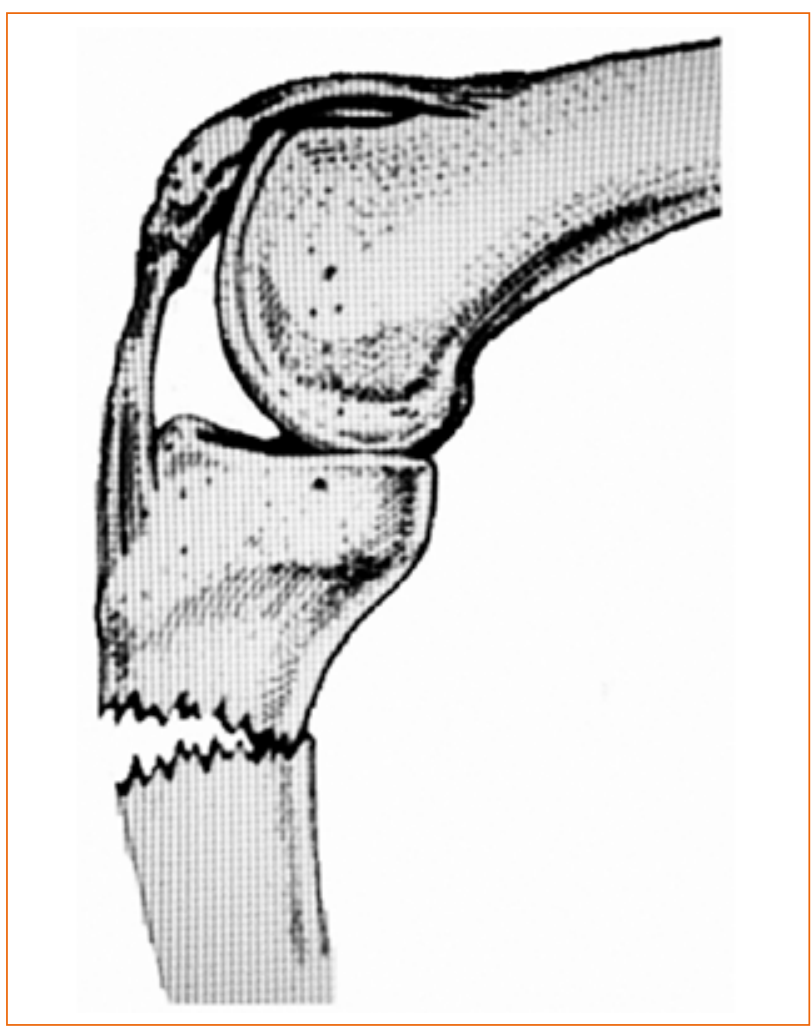

Şekil 5. Giriş noktasını posteriora alabilmek adına dizin fleksiyona zorlanması, kuadriseps gerginliğini arttırarak proksimal parçanın anterior angülasyonuna neden olur.

\section{POLLER VIDASI}

Valgus ve anterior angülasyon deformiteleri yalnızca, yukarıda sayılmış olan, travmatik nedenlerle oluşmaz. Intramedüller çivi ve medüller kanal çapı arasında ciddi fark varsa ve çivi-medulla teması yoksa çivi koronal planda laterale deviye olacaktır. Bunu engelleyebilmek adına çiviye komşu bir alana Poller veya block vidası yerleştirilebilir. Poller vidaları; intramedüller implantı sıkıştırmak veya rotasını değiştirmek amacıyla, yani bir anlamda, redüksiyona yardımcı cihaz gibi kullanılır. Poller vidaları, hem medüller kanalı daraltarak hem de kemik implant temasını arttırarak stabiliteye olumlu katkı sağlar. Yapılan çalışmalar, proksimalde iki tespit vidası olan çivilerle birlikte kullanılan Poller vidasının stabiliteye katkısının \%25 düzeyinde olduğunu ve sagittal plan deformitesini $5^{\circ}$ ye kadar düşürebildiğini ortaya koymuştur. ${ }^{[9]}$

Proksimal tibia kırıklarındaki kullanım teknikleri diğer kırıklardaki kullanımı ile aynı olan Poller vidaları; kısa parçaya, parçanın mümkün olan en distal kısmına 

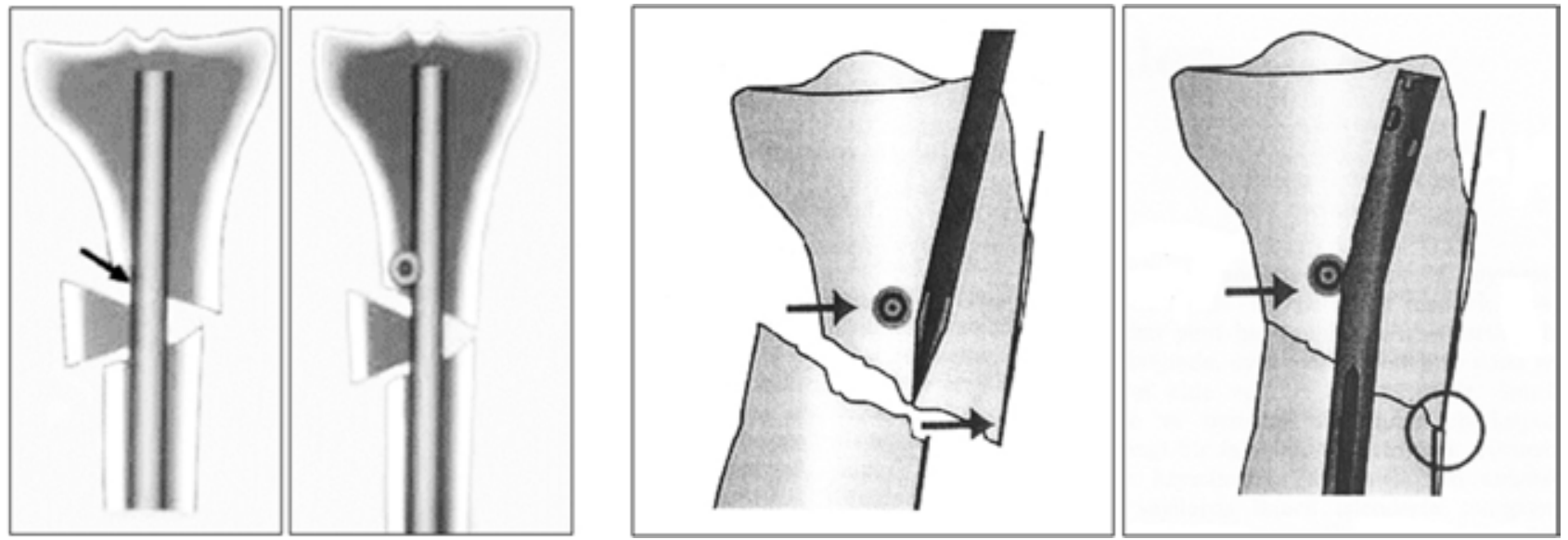

Şekil 6. Poller vidası; kısa parçaya, parçanın mümkün olan en distal kısmına ve açılanmanın iç bükey tarafına çift korteks olarak yerleştirilmelidir.

ve açılanmanın iç bükey tarafına çift korteks olarak yerleştirilen 4,5 mm'lik kortikal vidalardır (Şekil 6).

Proksimal parçanın çapının büyük, boyunun kısa ve üzerine yapışan kasların çekisine bağlı olarak lateral ve anteriora translase olması nedeniyle intramedüller çiviler ile tedaviye pek de uygun olmayan tibia üst uç kırıklarında kullanılan Poller vidaları, kırığın redüksiyonundan önce uygulanabilecekleri gibi, redüksiyonun yetersiz olduğu görüldükten sonra da uygulanabilir. Bu gibi durumlarda, çivinin yerleştirildiği medulladan geri çekilmesini takiben uygun pozisyonda yerleştirilen Poller vidası hem uygun dizilimin hem de stabilitenin teminini sağlayacaktır.

\section{UYGUN Çivi}

İntramedüller çiviler ile tedavi edilen proksimal tibia kırıklarında karşılaşılan sorunların nedenlerinden bir diğeri de bölgenin anatomik yapısıdır. Proksimal tibial metafiz ince bir korteksle çevrilmiş yoğun spongiyöz içeriğe sahiptir. Bu spongiyöz içerik gençlerde oldukça dens iken, yaş artışına paralel olarak kemikteki yapısal değişiklikler ve spongiyöz dokudaki dansite kaybına bağlı olarak medüller kanal çapı artar. Tibia cisim kırıklarında, çivi ile medüller kanal arasındaki temas dizilimin sağlanmasına yardım ederken, proksimal tibia kırıklarında bu temasın söz konusu olamaması nedeniyle yeterli stabilite elde edilemez. Sonuçta; çiviyi proksimal tibiaya tespit eden tespit vidası, en önemli stabilizan faktör haline gelir. ${ }^{[10]}$

İntramedüller implantların gerek tasarım gerekse de metalurjik açıdan, özellikle son 10 yıl içerisinde, geçirdiği evrim bahse konu sorunun çözümünü sağlayacak nitelikte görünmektedir. Hem tibianın posterior korteksinin perforasyonundan hem de eklem kıkırdağının harabiyetinden kaçınmanın en iyi yolu çiviye belli miktarda eğim vermektir. Çivinin proksimal kısmında bulunan ve ilk yapan kişinin adıyla anılan bu eğime Herzog eğimi adı verilir. Intramedüller çiviler; tam Herzog eğiminin bulunduğu noktada veya bunun hemen üzerinde, kırık parçaların birbirinden ayrılmasına neden olacak tarzda bir etki gücüne (wedge effect) sahiptir (Şekil 7). Yeni nesil çiviler, eğimlerinin daha üstte olması sayesinde bir yandan çivinin medüller kanala daha rahat itilmesini sağlarken bir yandan da wedge effect'e bağ|ı olarak ortaya çıkan proksimal parça translasyonunu minimalize eder. Bugün için ideal olarak kabul edilen Herzog eğimi; çivinin proksimal $50 \mathrm{~mm}$ 'sinde bulunan $8-10^{\circ}$ 'lik posterior eğimdir.

Proksimal kısmında farklı planlarda yönlenebilen kilit vidalarına sahip yeni tasarım çiviler, paralel kilit vidalarına sahip sistemlere göre daha ciddi bir stabilite sağlar. Transvers uzanımlı kilit vidaları çivinin mediyal-lateral plandaki translasyonunu önlerken, ikisi $45^{\circ}$ lik açlarla postero-lateral ve postero-mediyale, üçüncüsü ise direkt olarak posteriora yönlenen ilave kilit vidaları, çivinin varus-valgus ve daha az olarak, rotasyonel deformiteye neden olabilecek deforman güçlere olan direncini arttırlar ki bu durum kırık stabilitesinde yaklaşık \%50 oranında bir artış sağlar. Yapılan çalışmalar; üç oblik tespit vidası içeren çivi uygulamaları ile, mickey-mouse plakla birlikte konvansiyonel kilitli çivi uygulamalarına yakın stabilizasyon elde edildiğini, en proksimaldeki tespit vidasının ASLS (angular stable locking screw) vidası olarak kullanılmasının ise ilave bir stabilite sağladığını ortaya koymuştur. ${ }^{[11]}$ Ancak proksimal yerleşimli bu vidalar, popliteal arter ile tibial ve peroneal sinir ve tibal 


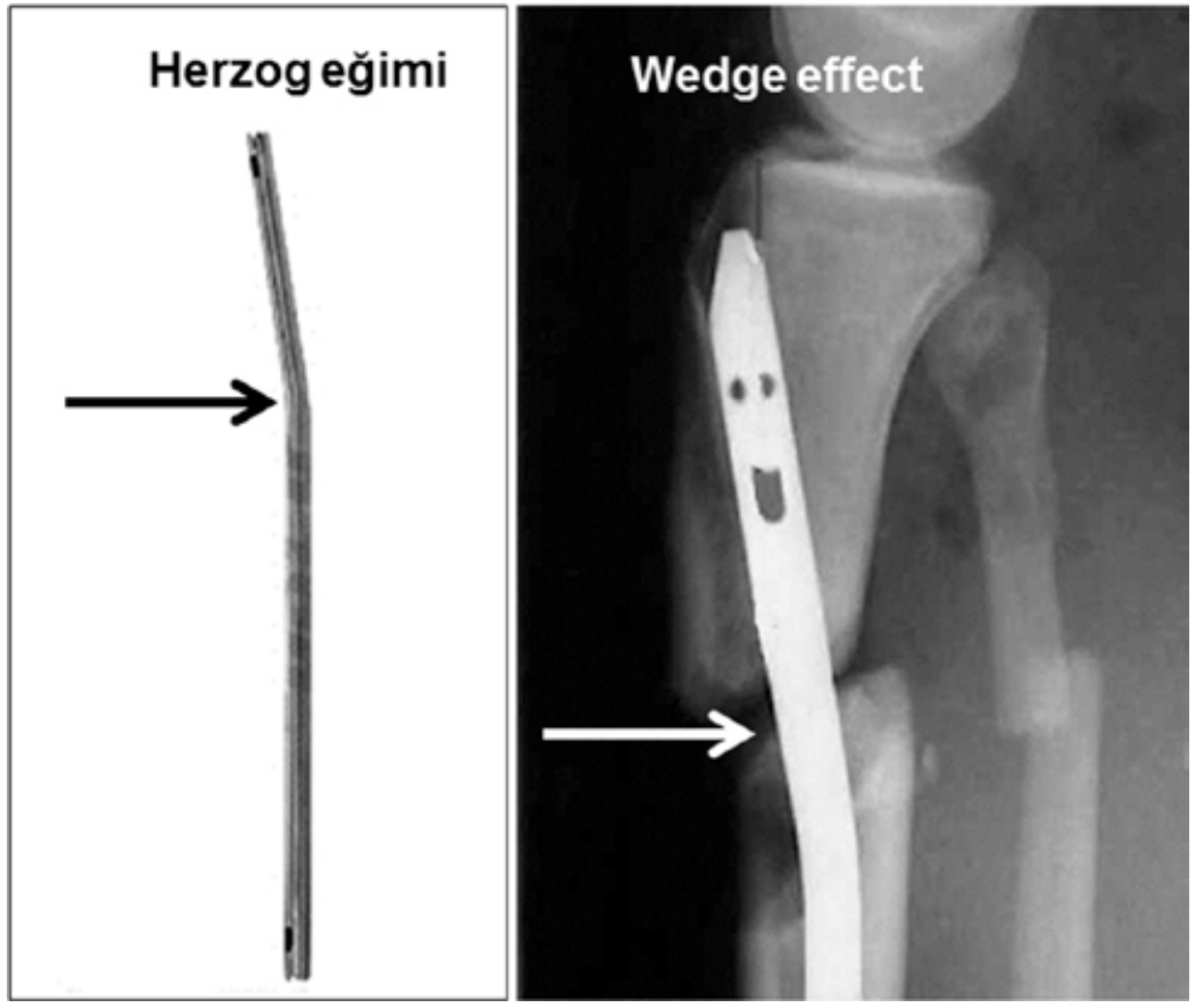

Şekil 7. İntramedüller çiviler tam Herzog eğiminin bulunduğu noktada veya bunun hemen üzerinde, kırık parçaların birbirinden ayrılmasına neden olacak tarzda bir etki gücüne (wedge effect) sahiptir.

eklem kıkırdağının yaralanması riski nedeniyle, mutlaka tek korteks olacak şekilde uygulanmalıdır.

İntramedüller implantlardaki gelişmeler, Herzog eğiminin yeri ve derecesi ile proksimal kilit vidası sayısının artışından ibaret değildir. Bilindiği üzere, daha kalın çivi daha fazla stabilite anlamına gelmektedir. Gövdeleri dar, oyucu başları küçük, keskin ve derin oyucu dişler içeren reamer'lar, daha az kortikal ısı ve daha çok canlı kemik hücresi elde edilmesi sağlayan "sınırlı oyma (ream to fit)" tekniğinin gelişmesini sağlamış, bu sayede de, daha geniş çaplı çiviler kullanılabilir hale gelmiştir ve bu çivilerde yorgunluk kırı̆̆ı görülme olasılığı çok daha azdır. ${ }^{[12]}$

Titanyum alaşımlı çiviler paslanmaz çelik çivilerle karşılaştırıldıklarında; daha iyi biyo-uyumluluk, kemiğinkine daha yakın bir elastik modulus, yorgunluğa dayanıklılık ve daha fazla esneme becerisine sahiptir. Günümüz teknolojisindeki gelişmeler sonrasında üretilmeye başlanan Tip II anodlanmış titanyum alaşımlı çivilerde bu özellikler çok daha belirgin hale gelmiştir. Aynı teknolojik gelişimden, dirençlerini sağlayan üç temel özelliği; üretildikleri materyal, gövde çapı ve yiv biçimi olan, kilit vidaları da pay almışlardır. ${ }^{[13]}$

Titanyumdan imal edilen kilit vidaları da, aynen çivilerde olduğu gibi, yorgunluk kırıklarına karşı çelik vidalardan daha dayanıklıdır. Düşük elastik modulusları sayesinde sahip oldukları fleksibiliteleri de diğer bir avantajlarıdır. ${ }^{[13]}$

Yapılan çalışmalar, vidaların dayanıklılıklarının gövde çaplarının üçüncü gücü kadar olduğunu ortaya koymuştur. Yani, vidanın çapı iki kat arttırılırsa, kırılmaya direnci sekiz kat artmaktadır. Daha kalın çiviler, daha kalın kilit vidalarının kullanılmasını olanaklı kıldıklarından, avantajlarını bir kat daha arttırmaktadır.

Solid bir çivinin deliğinden geçerek karşı kortekse ulaşan kilit vidasının yorgunluk kırığına direnci; çiviye temas ettiği noktadaki gövde çapı ile, sıyrılmaya karşı direnci ise; gövde çapı ve yiv derinliği ile ilgilidir. ${ }^{[13]}$ Bunun yanında, çift yivli helikal vidaların çivi-vida bileşkesindeki teması arttırarak, hem yorgunluk ve sıyrılmaya direnci hem de stabilite düzeyini arttırdıkları çalışmalar sonucunda tespit edilmiştir ki yeni nesil 
intramedüller implantların çoğu bu olumlu özellikleri bünyelerinde barındırmaktadır.

Sonuç olarak; proksimal tibia kırıklarının çivilenmesi oldukça zor olmakla birlikte, primer ve sekonder dizilim sorunlarının önüne geçilmek kaydıyla, intramedüller implantlarla da güvenle tedavi edilebileceklerini ve bu tedavi sonrasında oldukça iyi sonuçlar elde edilebileceğini söylemek mümkündür.

\section{KAYNAKLAR}

1. Ege R. Travmatoloji - Kırıklar Eklem Yaralanmaları, 4. Baskı. Ankara: Kadıoğlu Matbaası; 1989.

2. Lottes JO. Lottes Nailing. In: Browner BD, Edwards CC, editors. The Science and Practice of Intramedullary Nailing. Philadelphia: Lea \& Febiger; 1987. p.281-90.

3. Leach RE. Fractures of the Tibia and Fibula. In: Rockwood CA, Green DP, editors. Fractures in Adults, 2nd ed. Philadelphia: JB Lippincott Company; 1984. p.1593-663.

4. Rüedi TP, Murphy WM, editors, AO Principles of Fracture Management. Çeviri: Aksoy C. Tibia: üst uç. In: Aguş $\mathrm{H}$, editor. Kırık Tedavisinde AO Kuralları. İstanbul: Nobel Tıp Kitapları; 2000. p.499-517.

5. Kuhn S, Hansen M, Rommens PM. Extending the Indication of Intramedullary Nailing of Tibial Fractures. Eur J Trauma Emerg Surg 2007;33(2):159-69. Crossref

6. Hansen ST, Veith RG. Closed Küntscher Nailing of the Tibia. In: Browner BD, Edwards CC, editors. The Science and Practice of Intramedullary Nailing. Philadelphia: Lea \& Febiger; 1987. p.267-79.
7. Hernigou P, Cohen D. Proximal entry for intramedullary nailing of the tibia - The risk of unrecognised articular damage. J Bone Joint Surg Br 2000;82-B(1):33-41. Crossref

8. Eastman J, Tseng S, Lo E, Li CS, Yoo B, Lee M. Retropatellar Technique for Intramedullary Nailing of Proximal Tibia Fractures: A Cadaveric Assessment. J Orthop Trauma 2010;24(11):672-6. Crossref

9. Krettek C, Stephan C, Schandelmaier P, Richter M, Pape HC, Miclau T. The use of Poller screws as blocking in stabilishing tibial fractures treated with small diameter intramedullary nails. J Bone Joint Surg $\mathrm{Br}$ 1999;81$B(6): 963-8$. Crossref

10. Horn J, Linke B, Höntzsch D, Gueorguiev B, Schwieger $\mathrm{K}$. Angle stable interlocking screws improve construct stability of intramedullary nailing of distal tibia fractures: A biomechanical study. Injury 2009;40(7):767-71. Crossref

11. Kuhn S, Hansen M, Rommens PM. Extending the Indications of Intramedullary Nailing with the Expert Tibial Nail. Acta Chirurg Orthop et Traumatol Cechosl 2008;75(2):77-87.

12. Leung KS, Tagland G, Schnettler R, editors. Practise of Intramedullary Locked Nails. Çeviri: Özkayın N. Tibia Çivilemesindeki Yenilikler. In: Aktuğlu K, Okçu G, editors. Kanal İçi Çivilerin Pratiği. Antalya: İntertıp; 2010. p.99-108.

13. Leung KS, Tagland G, Schnettler R, editors. Practise of Intramedullary Locked Nails. Çeviri: Gümüşdağ H. İmplant ve Yüzeyler Arası İlişki Mühendisliği. In: Aktuğlu K, Okçu G, editors. Kanal İçi Çivilerin Pratiği. Antalya: İntertıp; 2010. p.67-81. 